\title{
Hexose-6-phosphate dehydrogenase: linking endocrinology and metabolism in the endoplasmic reticulum
}

\author{
Gábor Bánhegyi ${ }^{1,2}$, Miklós Csala ${ }^{2}$ and Angelo Benedetti ${ }^{1}$ \\ ${ }^{1}$ Dipartimento di Fisiopatologia, Medicina Sperimentale e Sanità Pubblica, Università di Siena, Via Aldo Moro, 53100 Siena, Italy \\ ${ }^{2}$ Department of Medical Chemistry, Molecular Biology and Pathobiochemistry, Semmelweis University \& MTA-SE Pathobiochemistry Research Group, 1444 Budapest, Hungary \\ (Correspondence should be addressed to A Benedetti; Email: benedetti@unisi.it)
}

\begin{abstract}
Hexose-6-phosphate dehydrogenase (H6PD) got into the focus of interest due to its role in the prereceptorial activation of glucocorticoids, which has been implicated in the pathomechanism of metabolic syndrome. Genetic observations, results gained in H6PD knockout mice, and studies on differentiating adipocytes demonstrated the importance of the enzyme in metabolic regulation. A nutrient-sensing function can be postulated for the enzyme, which links metabolism to endocrinology in the endoplasmic reticulum. This review provides an overview of the recent developments concerning the enzyme and its impact on various branches of the intermediary metabolism, which make it an important subject for the research on obesity, diabetes, and metabolic syndrome.
\end{abstract}

Journal of Molecular Endocrinology (2009) 42, 283-289

\section{Introduction}

The aim of the present review is to summarize the recently discovered roles of hexose-6-phosphate dehydrogenase (H6PD) in the intermediary metabolism, redox homeostasis, and signaling of the cell. Although the enzyme has been known for decades, it drew little attention until recent observations regarding its subcellular topology, tissue distribution, proteinprotein interactions, and especially its role in prereceptorial glucocorticoid activation. The novel findings have revealed that H6PD activity is an important link between the intermediary metabolism and the autocrine/paracrine effects of glucocorticoid hormones, and hence this enzyme should be considered as an intracellular nutrient sensor.

The endoplasmic reticulum (ER) as a metabolic compartment is involved in almost all important pathways of the intermediary metabolism (Csala et al. 2006). Accumulating evidence suggests that the ER plays a prominent role in nutrient sensing. The cells (hepatocytes, adipocytes, pancreatic $\beta$-cells, etc.) can adapt their ER capabilities to cope with the alterations of metabolic demand. Extreme metabolic conditions (either over- or undernutrition) result in ER stress sensed fundamentally by the luminal machinery of protein folding. ER stress causes the accumulation of immature proteins and triggers the unfolded protein response (UPR) that finally leads to a variety of downstream effects, such as apoptosis, inflammation, and insulin resistance (Hotamisligil 2005, Yoshida 2007, Zhang \& Kaufman 2008).

Recent observations have indicated that, besides the above signaling pathway, ER nutrient sensing can track alternative paths. Overfeeding stimulates intracellular activation of glucocorticoids in many cell types, and the concomitant autocrine and paracrine effects seem to be important elements of the pathomechanism of obesity, metabolic syndrome, and type 2 diabetes (Tomlinson et al. 2004, Morton \& Seckl 2008). H6PD emerged as an indispensable component of the intracellular glucocorticoid activating system. The alterations of the cellular metabolic state can affect the system through the activity of H6PD that is tightly coupled to the local production of glucocorticoids from inactive precursors in the ER lumen. Therefore, H6PD can be regarded as a metabolic sensor in the ER, which connects intermediary metabolism to hormonal signaling. In accordance with the sensor function, H6PD seems to be a ubiquitous enzyme with a moderate inducibility implying that the substrate supply rather than enzyme level defines its activity. The wide distribution suggests that H6PD is also a housekeeping enzyme, playing a prosurvival role by maintaining the redox homeostasis of the ER/SR lumen. The enzymology and physiological functions of H6PD have been delineated by 
excellent recent reviews (Hewitt $e t$ al. 2005, White $e t$ al. 2007, 2008); therefore, the main properties of H6PD are only briefly summarized in Table 1 .

\section{Prereceptorial glucocorticoid activation in health and disease}

Glucocorticoid hormones form an important component of the homeostatic control mechanisms that, together with the immune system and autonomic nervous system, are critical in adapting to environmental challenges and thus maintain stability through change over time. Glucocorticoids regulate pathways leading to cellular proliferation, differentiation, or death, those induced (or repressed) in response to infection, tissue damage, and inflammation, pathways that maintain metabolic homeostasis and those that regulate mood and memory (Stahn et al. 2007). The relative expression levels of glucocorticoid receptors $\alpha$ and $\beta$ (Lewis-Tuffin \& Cidlowski 2006) as well as the intracellular level of the hormone are the principal determinants of the glucocorticoid action. Since inactive glucocorticoids constitute a major fraction in the blood, the intracellular level of the hormonally active form critically depends upon the prereceptorial activation of glucocorticoids by $11 \beta$ hydroxysteroid dehydrogenase type 1 (HSD11B1) (Tomlinson et al. 2004, Morton \& Seckl 2008). By converting intrinsically inert glucocorticoids (cortisone, 11-dehydrocorticosterone) into their active forms (cortisol, corticosterone), HSD11B1 increases

Table 1 Biochemical properties of hexose-6-phosphate dehydrogenase (H6PD)

$89 \mathrm{kDa}$ molecular mass Mason et al. (1999) and Clarke \& Mason (2003)

Human H6PD gene on 1p36, spanning $37 \mathrm{~kb}$; five exons and four introns Mason et al. (1999)

Expression in almost every organ and cell type Hewitt et al. (2005)

Intraluminal positioning in the ER Ozols (1993)

Lack of identifiable membrane-spanning region or ER retention signal Ozols (1993)

Protein-protein interaction with HSD11B1 Atanasov et al. (2008)

Glucose-6-phosphate dehydrogenase plus 6-phosphogluconolactonase activities Collard et al. (1999) and Clarke \& Mason (2003)

Potential substrates: glucose-6-phosphate, galactose-6-phosphate, 2-deoxyglucose-6-phosphate, glucosamine-6-phosphate, and glucose-6-sulfate Clarke \& Mason (2003)

Specificity is ensured by the glucose-6-phosphate transporter of the ER, which is selective to glucose-6-phosphate van Schaftingen \& Gerin (2002), Banhegyi et al. (2004) and Marcolongo et al. (2007)

Potential coenzymes: NADP ${ }^{+}, \mathrm{NAD}^{+}$, or deamino-NADP ${ }^{+}$ Beutler \& Morrison (1967) and Clarke \& Mason (2003) Modest inhibition by steroids and NADPH Oka et al. (1981) glucocorticoid access to receptors. Alterations of HSD11B1 expression and activity have been implicated in the pathomechanism of hypertension, type 2 diabetes, atherosclerosis, metabolic syndrome, obesity, age-related cognitive dysfunction, osteoporosis, arthritis, and many other human diseases (Stimson \& Walker 2007, Chapman \& Seckl 2008, Pierotti et al. 2008).

\section{HSD11B1 activity is determined by the $[\mathrm{NADPH}] /\left[\mathrm{NADP}^{+}{ }^{+}\right.$ratio}

HSD11B1 enzyme is an integral membrane protein of the ER with luminal active site (Ozols 1995, Mziaut et al. 1999, Odermatt et al. 1999). It catalyzes the interconversion between cortisone and cortisol using NADPH or $\mathrm{NADP}^{+}$coenzyme. Although the reaction is reversible in vitro, the enzyme acts as a reductase in vivo. Due to the relatively low free enthalpy change of the reaction, the enzyme activity greatly depends on the [NADPH]/ $\left[\mathrm{NADP}^{+}\right]$ratio in the ER lumen (Atanasov et al. 2004, Banhegyi et al. 2004, Bujalska et al. 2005). Although the origin, the exact composition, and the redox state of luminal pyridine nucleotides are unknown, several indirect observations show that they are separated by the membrane barrier from the cytosolic pool (Czegle et al. 2006, Piccirella et al. 2006). The redox state of the cytosolic pyridine nucleotides is determined by several oxidoreductases. By contrast, H6PD seems to be the major - if not the only - enzyme responsible for NADP ${ }^{+}$ reduction in the ER lumen (Hewitt et al. 2005). Furthermore, according to the present knowledge, the substrate supply for H6PD is ensured by a sole ER membrane protein, the glucose-6-phosphate transporter (G6PT). Thus, in the ER of hepatocyte, adipocyte, and neutrophil granulocyte (and possibly a number of other cells), HSD11B1 can be considered as a component of a complex system, which also includes H6PD and G6PT (Fig. 1). The cooperation of the three proteins is ensured by sharing a common separate pyridine nucleotide pool.

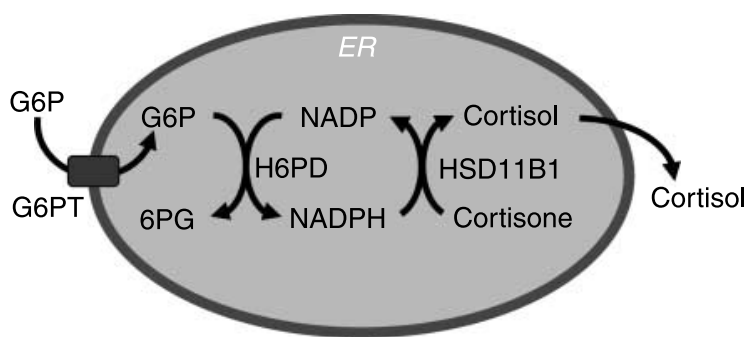

Figure 1 Scheme of the G6PT-H6PD-HSD11B1 triad in the ER. Glucose-6-phosphate (G6P) is transported by G6P transporter (G6PT) to the ER lumen, where it is converted to phosphogluconate (6PG) by H6PD in a redox reaction generating NADPH. HSD11B1 utilizes NADPH as cofactor, allowing the conversion of cortisone to cortisol. 
Theoretically, these circumstances can make the G6PT-H6PD-HSD11B1 system an excellent metabolic sensor of the ER. Minor changes in the [NADPH]/ $\left[\mathrm{NADP}^{+}\right]$ratio in a small compartment can lead to significant alterations in glucocorticoid activation. In fact, an about tenfold excess of NADPH is required for the appropriate functioning of HSD11B1 as a reductase; a dramatic increase in the activity starts at 9:1 $[\mathrm{NADPH}] /\left[\mathrm{NADP}^{+}\right]$ratio (Dzyakanchuk et al. 2008). It means that the in vivo set point of the NADPH$\mathrm{NADP}^{+}$redox couple is much more reduced in the ER lumen than in the cytosol (Díaz-Flores et al. 2006, Pollak et al. 2007, Panten \& Rustenbeck 2008). H6PD is more resistant to feedback inhibition by NADPH than its cytosolic counterpart glucose-6-phosphate dehydrogenase (Oka et al. 1981), which allows the almost complete reduction of the ER luminal pyridine nucleotide pool. The redox state of luminal NADPH/NADP ${ }^{+}$ system is defined by cytosolic glucose-6-phosphate level with the transmission of G6PT and H6PD.

\section{Intracellular glucose-6-phosphate concen- tration as a function of nutrient load}

Intracellular glucose-6-phosphate concentration is a function of blood glucose and insulin levels in insulinsensitive non-gluconeogenic tissues such as adipose tissue and skeletal muscle (Denton et al. 1966, Sekar et al. 1998). Insulin-dependent translocation of GLUT4 glucose transporter (SLC2A4) into the plasma membrane enhances glucose uptake, which results in elevated intracellular glucose-6-phosphate level. Accumulated glucose-6-phosphate fuels the G6PT-H6PDHSD11B1 triad, which finally leads to increased prereceptorial activation of glucocorticoids (Fig. 2). In gluconeogenic tissues, intracellular glucose-6-phosphate concentration is less fluctuating; however, it can be elevated by intense gluconeogenesis in starvation (Hems \& Brosnan 1971).

The system is also suitable for the indirect sensing of fatty acid levels. According to Randle's hypothesis (glucose-fatty acid cycle), free fatty acids compete with glucose for substrate oxidation. Increased free fatty acid levels lead to elevated mitochondrial [acetyl-CoA]/ $[\mathrm{CoA}]$ and $[\mathrm{NADH}] /\left[\mathrm{NAD}^{+}\right]$ratios that inhibit pyruvate dehydrogenase activity and lead to an increase in citrate levels, which, in turn, decreases phosphofructokinase activity and hence induces an increase in glucose6-phosphate concentration due to the inhibition of glycolysis (Randle et al. 1963, Randle 1998; Fig. 2).

In conclusion, overfeeding either by carbohydrates or lipids results in elevated glucose-6-phosphate level in adipose tissue and skeletal muscle. These conditions, in fact, are accompanied by enhanced glucocorticoid activation. In humans, 'whole-body' generation of cortisol by HSD11B1 increases within 2-3 h after consumption of a mixed meal (Basu et al. 2006). Similarly, hyperinsulinemia and elevated free fatty acid level induce an acute increase in HSD11B1 activity in adipose tissue in humans (Wake et al. 2006). A very recent study has shown that luminal NADPH concentration in the ER is highly sensitive to extracellular glucose levels in HEK-293 cells expressing HSD11B1. Lowering glucose in the culture medium dose dependently decreased the reductase activity of HSD11B1 and diminished the cortisol/cortisone ratio. Coexpression with H6PD potentiated the reductase activity of HSD11B1 at high glucose concentration (Dzyakanchuk et al. 2008). However, the same study points out that other cell types (H4IIE liver cells and 3T3-L1 adipocytes) are less sensitive to the changes in extracellular glucose concentration. The glucose-6-phosphate availability in the ER lumen changes dramatically in two subtypes of the glycogen storage disease type 1 (GSD1). The observation that G6PT deficiency (GSD1b) significantly reduces while glucose-6-phosphatase deficiency (GSD1a) remarkably increases HSD11B1 activity strongly supports our hypothesis and proves the participation of G6PT in glucose (or glucose-6phosphate) sensing (Walker et al. 2007). A complex disorder of nutrient sensing and metabolic regulation was observed in H6PD knockout mice: fasting hypoglycemia, low hepatic glycogen content, increased sensitivity to insulin, and decreased negative feedback on the hypothalamic-pituitary-adrenal axis (Lavery et al. 2006, 2007, Rogoff et al. 2007). These findings raise the important possibility that the G6PT-H6PD-HSD11B1 system plays a key role in the dynamic modifications of the acute metabolic response to feeding. The acute responsiveness suggests that the activity rather than the expression of H6PD is important in the coupling between metabolism and hormonal response.

The functioning of the system has been evidenced also in specialized endocrine cells involved in the regulation of whole-body metabolism. Local activation of glucocorticoids is required for the inhibition of glucagon secretion in the $\alpha$-cells of pancreatic islets (Swali et al. 2008). The effect of inactive glucocorticoid precursors is abolished in H6PD-null mice or when the HSD11B1 activity is reduced with specific inhibitors (Lavery et al. 2006).

\section{Pathobiochemical aspects}

Beyond the physiological sensor mechanism, the G6PTH6PD-HSD11B1 triad can participate in the pathomechanism of gluco-, lipo-, and glucolipotoxicity. Glucose and fatty acids activate the UPR and induce ER stress by an unknown mechanism. It can be supposed that the excess of reducing equivalents leads to a redox imbalance in the ER lumen with a concomitant ER stress 


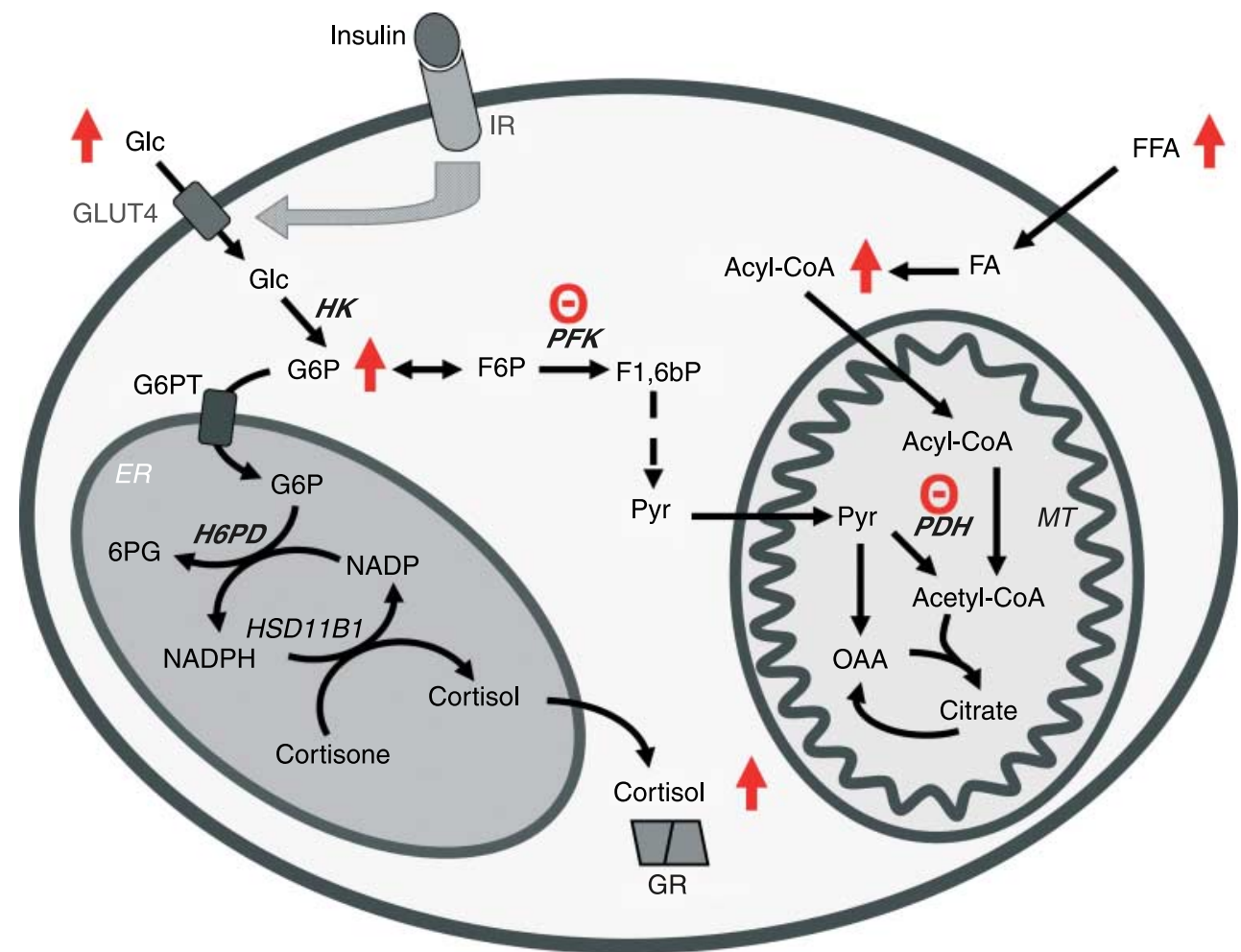

Figure 2 The role of the G6PT-H6PD-HSD11B1 triad in nutrient sensing of insulin-sensitive cells. Insulin stimulates the translocation of GLUT4 into the plasma membrane and hence enhances glucose uptake in muscle and adipose tissue, which results in elevated intracellular glucose-6-phosphate (G6P) level. On the other hand, high level of free fatty acids - according to Randle's 'glucose-fatty acid cycle' - inhibits glucose catabolism at several key steps, most importantly at the level of the pyruvate dehydrogenase (PDH) reaction. As a consequence, glucose-6-phosphate accumulates within the cell. Accumulation of glucose-6phosphate, in turn, fuels the G6PT-H6PD-HSD11B1 system, which leads to increased prereceptorial activation of glucocorticoids. Thus, oversupply of reducing equivalents - in the form of either carbohydrates or lipids - leads to the enhancement of glucocorticoid activation. Increasing concentrations are indicated by red arrows, and resulting enzyme inhibitions are also indicated in red. Abbreviations: FFA, free fatty acid; F6P, fructose-6-phosphate; F1,6bP, fructose-1,6-bisphosphate; Glc, glucose; G6P, glucose-6-phosphate; GR, glucocorticoid receptor; HK, hexokinase; IR, insulin receptor; MT, mitochondrion; PDH, pyruvate dehydrogenase; PFK, phosphofructokinase; Pyr, pyruvate and OAA, oxaloacetate.

(Banhegyi et al. 2007). On the other hand, pharmacological or genetic manipulation of the G6PTH6PD-HSD11B1 triad leads to ER stress, UPR, and/or apoptosis in various cell types (Leuzzi et al. 2003, Belkaid et al. 2006, Kardon et al. 2008, Lavery et al. 2008) because of a deficiency in the production of reducing equivalents. The ER stress response and its effectors are activated to protect the cells from apoptosis; however, the activation of these processes under conditions of long-term elevation of free fatty acids and glucose can lead to cellular dysfunction and ultimately apoptosis. Pancreatic $\beta$-cells are especially sensitive to glucolipotoxicity, perhaps not independently from their metabolic sensor function; high capacity of nutrient sensing is necessarily accompanied by a reduced protection against nutrient toxicity (Wang et al. 2005, Chang-Chen et al. 2008, Hou et al. 2008). However, saturated fatty acids disrupt ER homeostasis and induce ER stress and apoptosis also in liver cells (Wei et al. 2006).

An additional interesting point relates to the involvement of H6PD in the formation of atherogenic hydroxysterols. Actually it has been observed that 7-ketosterols (Hult et al. 2004, Schweizer et al. 2004) and 7-keto neurosteroids (Nashev et al. 2007) are substrates and competitive inhibitors of HSD11B1. Potentially, the redox balance of oxysterols, determined by H6PD/HSD11B1, may be crucial in modulating glucocorticoid and oxysterol effects (Balazs et al. 2008, Wamil et al. 2008).

Taking it all-round, high nutrient (electron donor) intake in the form of either carbohydrates or lipids can lead to enhanced glucocorticoid activation, especially in insulin-sensitive, non-gluconeogenic tissues. It has been known for a long while that glucocorticoids induce a 
state of insulin resistance by directly inhibiting the translocation of the GLUT4 glucose transporters to the plasma membrane and by decreased sensitivity of glycogen synthesis and glucose oxidation to insulin in skeletal muscle (Rizza et al. 1982, Dimitriadis et al. 1997). Moreover, elevated local activation of glucocorticoids stimulates preadipocyte differentiation, increases the expression of lipoprotein lipase, glycerol production, and triglyceride synthesis in visceral adipose tissue and stimulates hepatic gluconeogenesis, thereby contributing to the development of the metabolic syndrome (Bujalska et al. 2008, Tomlinson et al. 2008).

In conclusion, overnutrition (excess of reducing power) causes the elevation of intracellular glucose-6phosphate level, which activates H6PD via G6PT. The generated and maintained high $[\mathrm{NADPH}] /\left[\mathrm{NADP}^{+}\right]$ ratio in the ER lumen supports glucocorticoid activation by HSD11B1. High local glucocorticoid levels counter-regulate insulin action and promote nutrient storage, hence producing the most characteristic features of the metabolic syndrome. The role of HSD11B1 in metabolism-dependent autocrine and paracrine effects is supported by growing evidence; however, the mechanism may be more general in endocrinology. Although the subcellular localization of steroid oxidoreductases has not been systematically investigated, the different preferences of the isoenzymes to reductase or dehydrogenase activity - e.g. in case of 17ß-hydroxysteroid dehydrogenase family (Luu-The 2001) - suggest that their active sites might be localized in different compartments of the cell and that the reductase activity might be due to colocalization and functional cooperation with H6PD.

\section{Declaration of interest}

The authors have nothing to disclose. The authors declare that there is no conflict of interest that would prejudice the impartiality of this scientific work.

\section{Funding}

This research did not receive any specific grant from any funding agency in the public, commercial or not-for-profit sector.

\section{Acknowledgements}

Thanks are due to the János Bolyai Research Scholarship of the Hungarian Academy of Sciences.

\section{References}

Atanasov AG, Nashev LG, Schweizer RA, Frick C \& Odermatt A 2004 Hexose-6-phosphate dehydrogenase determines the reaction direction of 11 $\beta$-hydroxysteroid dehydrogenase type 1 as an oxoreductase. FEBS Letters 571 129-133.
Atanasov AG, Nashev LG, Gelman L, Legeza B, Sack R, Portmann R \& Odermatt A 2008 Direct protein-protein interaction of 11ßhydroxysteroid dehydrogenase type 1 and hexose-6-phosphate dehydrogenase in the endoplasmic reticulum lumen. Biochimica et Biophysica Acta 1783 1536-1543.

Balazs Z, Nashev LG, Chandsawangbhuwana C, Baker ME \& Odermatt A 2008 Hexose-6-phosphate dehydrogenase modulates the effect of inhibitors and alternative substrates of $11 \beta$-hydroxysteroid dehydrogenase 1. Molecular and Cellular Endocrinology (doi: 10.1016/j.mce.2008.10.021).

Banhegyi G, Benedetti A, Fulceri R \& Senesi S 2004 Cooperativity between $11 \beta$-hydroxysteroid dehydrogenase type 1 and hexose-6phosphate dehydrogenase in the lumen of the endoplasmic reticulum. Journal of Biological Chemistry 279 27017-27021.

Banhegyi G, Benedetti A, Csala M \& Mandl J 2007 Stress on redox. FEBS Letters 581 3634-3640.

Basu R, Singh R, Basu A, Johnson CM \& Rizza RA 2006 Effect of nutrient ingestion on total-body and splanchnic cortisol production in humans. Diabetes 55 667-674.

Belkaid A, Copland IB, Massillon D \& Annabi B 2006 Silencing of the human microsomal glucose-6-phosphate translocase induces glioma cell death: potential new anticancer target for curcumin. FEBS Letters 580 3746-3752.

Beutler E \& Morrison M 1967 Localization and characteristics of hexose 6-phosphate dehydrogenase (glucose dehydrogenase). Journal of Biological Chemistry 242 5289-5293.

Bujalska IJ, Draper N, Michailidou Z, Tomlinson JW, White PC, Chapman KE, Walker EA \& Stewart PM 2005 Hexose-6-phosphate dehydrogenase confers oxo-reductase activity upon 11 $\beta$-hydroxysteroid dehydrogenase type 1. Journal of Molecular Endocrinology 34 675-684.

Bujalska IJ, Hewitt KN, Hauton D, Lavery GG, Tomlinson JW, Walker EA \& Stewart PM 2008 Lack of hexose-6-phosphate dehydrogenase impairs lipid mobilization from mouse adipose tissue. Endocrinology 149 2584-2591.

Chang-Chen KJ, Mullur R \& Bernal-Mizrachi E 2008 -Cell failure as a complication of diabetes. Reviews in Endocrine and Metabolic Disorders 9 329-343.

Chapman KE \& Seckl JR 2008 11ß-HSD1, inflammation, metabolic disease and age-related cognitive (dys)function. Neurochemical Research 33 624-636.

Clarke JL \& Mason PJ 2003 Murine hexose-6-phosphate dehydrogenase: a bifunctional enzyme with broad substrate specificity and 6-phosphogluconolactonase activity. Archives of Biochemistry and Biophysics 415 229-234.

Collard F, Collet JF, Gerin I, Veiga-da-Cunha M \& Van Schaftingen E 1999 Identification of the cDNA encoding human 6-phosphogluconolactonase, the enzyme catalyzing the second step of the pentose phosphate pathway(1). FEBS Letters 459 223-226.

Csala M, Banhegyi G \& Benedetti A 2006 Endoplasmic reticulum: a metabolic compartment. FEBS Letters 580 2160-2165.

Czegle I, Piccirella S, Senesi S, Csala M, Mandl J, Banhegyi G, Fulceri R $\&$ Benedetti A 2006 Cooperativity between 11ß-hydroxysteroid dehydrogenase type 1 and hexose-6-phosphate dehydrogenase is based on a common pyridine nucleotide pool in the lumen of the endoplasmic reticulum. Molecular and Cellular Endocrinology $\mathbf{2 4 8}$ 24-25.

Denton RM, Yorke RE \& Randle PJ 1966 Measurement of concentrations of metabolites in adipose tissue and effects of insulin, alloxan-diabetes and adrenaline. Biochemical Journal 100 407-419.

Díaz-Flores M, Ibanez-Hernandez MA, Galvan RE, Gutierrez M, DuranReyes G, Medina-Navarro R, Pascoe-Lira D, Ortega-Camarillo C, Vilar-Rojas C, Cruz M et al. 2006 Glucose-6-phosphate dehydrogenase activity and $\mathrm{NADPH} / \mathrm{NADP}^{+}$ratio in liver and pancreas are dependent on the severity of hyperglycemia in rat. Life Sciences $\mathbf{7 8}$ 2601-2607. 
Dimitriadis G, Leighton B, Parry-Billings M, Sasson S, Young M, Krause U, Bevan S, Piva T, Wegener G \& Newsholme EA 1997 Effects of glucocorticoid excess on the sensitivity of glucose transport and metabolism to insulin in rat skeletal muscle. Biochemical Journal 321 $707-712$.

Dzyakanchuk AA, Balazs Z, Nashev LG, Amrein KE \& Odermatt A 2008 $11 \beta$-Hydroxysteroid dehydrogenase 1 reductase activity is dependent on a high ratio of $\mathrm{NADPH} / \mathrm{NADP}(+)$ and is stimulated by extracellular glucose. Molecular and Cellular Endocrinology (doi: 10.1016/jmce.2008.08.009).

Hems DA \& Brosnan JT 1971 Effects of metabolic acidosis and starvation on the content of intermediary metabolites in rat kidney. Biochemical Journal 123 391-397.

Hewitt KN, Walker EA \& Stewart PM 2005 Minireview: hexose-6phosphate dehydrogenase and redox control of 11ß-hydroxysteroid dehydrogenase type 1 activity. Endocrinology 146 2539-2543.

Hotamisligil GS 2005 Role of endoplasmic reticulum stress and c-Jun NH2-terminal kinase pathways in inflammation and origin of obesity and diabetes. Diabetes 54 S73-S78.

Hou ZQ, Li HL, Gao L, Pan L, Zhao JJ \& Li GW 2008 Involvement of chronic stresses in rat islet and INS-1 cell glucotoxicity induced by intermittent high glucose. Molecular and Cellular Endocrinology 291 $71-78$.

Hult M, Elleby B, Shafqat N, Svensson S, Rane A, Jornvall H, Abrahmsen L \& Oppermann U 2004 Human and rodent type $111 \beta$ hydroxysteroid dehydrogenases are $7 \beta$-hydroxycholesterol dehydrogenases involved in oxysterol metabolism. Cellular and Molecular Life Sciences 61 992-999.

Kardon T, Senesi S, Marcolongo P, Legeza B, Banhegyi G, Mandl J, Fulceri R \& Benedetti A 2008 Maintenance of luminal NADPH in the endoplasmic reticulum promotes the survival of human neutrophil granulocytes. FEBS Letters 582 1809-1815.

Lavery GG, Walker EA, Draper N, Jeyasuria P, Marcos J, Shackleton CH, Parker KL, White PC \& Stewart PM 2006 Hexose-6-phosphate dehydrogenase knock-out mice lack $11 \beta$-hydroxysteroid dehydrogenase type 1-mediated glucocorticoid generation. Journal of Biological Chemistry 281 6546-6551.

Lavery GG, Hauton D, Hewitt KN, Brice SM, Sherlock M, Walker EA \& Stewart PM 2007 Hypoglycemia with enhanced hepatic glycogen synthesis in recombinant mice lacking hexose-6-phosphate dehydrogenase. Endocrinology 148 6100-6106.

Lavery GG, Walker EA, Turan N, Rogoff D, Ryder JW, Shelton JM, Richardson JA, Falciani F, White PC, Stewart PM et al. 2008 Deletion of hexose-6-phosphate dehydrogenase activates the unfolded protein response pathway and induces skeletal myopathy. Journal of Biological Chemistry 283 8453-8461.

Leuzzi R, Banhegyi G, Kardon T, Marcolongo P, Capecchi PL, Burger HJ, Benedetti A \& Fulceri R 2003 Inhibition of microsomal glucose-6-phosphate transport in human neutrophils results in apoptosis: a potential explanation for neutrophil dysfunction in glycogen storage disease type 1b. Blood 101 2381-2387.

Lewis-Tuffin LJ \& Cidlowski JA 2006 The physiology of human glucocorticoid receptor $\beta$ (hGR $\beta$ ) and glucocorticoid resistance. Annals of the New York Academy of Sciences 1069 1-9.

Luu-The V 2001 Analysis and characteristics of multiple types of human 17ß-hydroxysteroid dehydrogenase. Journal of Steroid Biochemistry and Molecular Biology 76 143-151.

Marcolongo P, Piccirella S, Senesi S, Wunderlich L, Gerin I, Mandl J, Fulceri R, Banhegyi G \& Benedetti A 2007 The glucose-6-phosphate transporter-hexose-6-phosphate dehydrogenase-11 $\beta$-hydroxysteroid dehydrogenase type 1 system of the adipose tissue. Endocrinology 148 2487-2495.

Mason PJ, Stevens D, Diez A, Knight SW, Scopes DA \& Vulliamy TJ 1999 Human hexose-6-phosphate dehydrogenase (glucose 1-dehydrogenase) encoded at 1p36: coding sequence and expression. Blood Cells, Molecules EO Diseases 25 30-37.

Morton NM \& Seckl JR 2008 11ß-Hydroxysteroid dehydrogenase type 1 and obesity. Frontiers of Hormone Research 36 146-164.
Mziaut H, Korza G, Hand AR, Gerard C \& Ozols J 1999 Targeting proteins to the lumen of endoplasmic reticulum using N-terminal domains of $11 \beta$-hydroxysteroid dehydrogenase and the $50-\mathrm{kDa}$ esterase. Journal of Biological Chemistry 274 14122-14129.

Nashev LG, Chandsawangbhuwana C, Balazs Z, Atanasov AG, Dick B, Frey FJ, Baker ME \& Odermatt A 2007 Hexose-6-phosphate dehydrogenase modulates $11 \beta$-hydroxysteroid dehydrogenase type 1-dependent metabolism of 7-keto- and 7 $\beta$-hydroxy-neurosteroids. PLOS ONE 2 e561.

Odermatt A, Arnold P, Stauffer A, Frey BM \& Frey FJ 1999 The $\mathrm{N}$-terminal anchor sequences of $11 \beta$-hydroxysteroid dehydrogenases determine their orientation in the endoplasmic reticulum membrane. Journal of Biological Chemistry 274 28762-28770.

Oka K, Takahashi T \& Hori SH 1981 Differential effects of the $\mathrm{NADPH} / \mathrm{NADP}^{+}$ratio on the activities of hexose-6-phosphate dehydrogenase and glucose-6-phosphate dehydrogenase. Biochimica et Biophysica Acta 662 318-325.

Ozols J 1993 Isolation and the complete amino acid sequence of lumenal endoplasmic reticulum glucose-6-phosphate dehydrogenase. PNAS 90 5302-5306.

Ozols $J 1995$ Lumenal orientation and post-translational modifications of the liver microsomal $11 \beta$-hydroxysteroid dehydrogenase. Journal of Biological Chemistry 270 2305-2312.

Panten U \& Rustenbeck I 2008 Fuel-induced amplification of insulin secretion in mouse pancreatic islets exposed to a high sulfonylurea concentration: role of the NADPH/ $\mathrm{NADP}^{+}$ratio. Diabetologia $\mathbf{5 1}$ 101-109.

Piccirella S, Czegle I, Lizak B, Margittai E, Senesi S, Papp E, Csala M, Fulceri R, Csermely P, Mandl J et al. 2006 Uncoupled redox systems in the lumen of the endoplasmic reticulum. Pyridine nucleotides stay reduced in an oxidative environment. Journal of Biological Chemistry 281 4671-4677.

Pierotti S, Gandini L, Lenzi A \& Isidori AM 2008 Pre-receptorial regulation of steroid hormones in bone cells: insights on glucocorticoid-induced osteoporosis. Journal of Steroid Biochemistry and Molecular Biology 108 292-299.

Pollak N, Dolle C \& Ziegler M 2007 The power to reduce: pyridine nucleotides - small molecules with a multitude of functions. Biochemical Journal 402 205-218.

Randle PJ 1998 Regulatory interactions between lipids and carbohydrates: the glucose fatty acid cycle after 35 years. Diabetes/Metabolism Reviews 14 263-283.

Randle PJ, Garland PB, Hales CN \& Newsholme EA 1963 The glucose fatty-acid cycle. Its role in insulin sensitivity and the metabolic disturbances of diabetes mellitus. Lancet 1 785-789.

Rizza RA, Mandarino LJ \& Gerich JE 1982 Cortisol-induced insulin resistance in man: impaired suppression of glucose production and stimulation of glucose utilization due to a postreceptor detect of insulin action. Journal of Clinical Endocrinology and Metabolism $\mathbf{5 4}$ 131-138.

Rogoff D, Ryder JW, Black K, Yan Z, Burgess SC, McMillan DR \& White PC 2007 Abnormalities of glucose homeostasis and the hypothalamic-pituitary-adrenal axis in mice lacking hexose-6phosphate dehydrogenase. Endocrinology 148 5072-5080.

van Schaftingen E \& Gerin I 2002 The glucose-6-phosphatase system. Biochemical Journal 362 513-532.

Schweizer RA, Zurcher M, Balazs Z, Dick B \& Odermatt A 2004 Rapid hepatic metabolism of 7-ketocholesterol by $11 \beta$-hydroxysteroid dehydrogenase type 1: species-specific differences between the rat, human, and hamster enzyme. Journal of Biological Chemistry $\mathbf{2 7 9}$ 18415-18424.

Sekar N, Qian S \& Shechter Y 1998 Vanadate elevates lipogenicity of starved rat adipose tissue: mechanism of action. Endocrinology 139 2514-2518.

Stahn C, Lowenberg M, Hommes DW \& Buttgereit F 2007 Molecular mechanisms of glucocorticoid action and selective glucocorticoid receptor agonists. Molecular and Cellular Endocrinology 275 71-78. 
Stimson RH \& Walker BR 2007 Glucocorticoids and 11ß-hydroxysteroid dehydrogenase type 1 in obesity and the metabolic syndrome. Minerva Endocrinologica 32 141-159.

Swali A, Walker EA, Lavery GG, Tomlinson JW \& Stewart PM 2008 11ßHydroxysteroid dehydrogenase type 1 regulates insulin and glucagon secretion in pancreatic islets. Diabetologia 51 2003-2011.

Tomlinson JW, Walker EA, Bujalska IJ, Draper N, Lavery GG, Cooper MS, Hewison M \& Stewart PM 2004 11ß-Hydroxysteroid dehydrogenase type 1: a tissue-specific regulator of glucocorticoid response. Endocrine Reviews 25 831-866.

Tomlinson JW, Finney J, Hughes BA, Hughes SV \& Stewart PM 2008 Reduced glucocorticoid production rate, decreased 5alphareductase activity, and adipose tissue insulin sensitization after weight loss. Diabetes 57 1536-1543.

Wake DJ, Homer NZ, Andrew R \& Walker BR 2006 Acute in vivo regulation of $11 \beta$-hydroxysteroid dehydrogenase type 1 activity by insulin and intralipid infusions in humans. Journal of Clinical Endocrinology and Metabolism 91 4682-4688.

Walker EA, Ahmed A, Lavery GG, Tomlinson JW, Kim SY, Cooper MS, Ride JP, Hughes BA, Shackleton CH, McKiernan P et al. 2007 11ßHydroxysteroid dehydrogenase type 1 regulation by intracellular glucose 6-phosphate provides evidence for a novel link between glucose metabolism and hypothalamo-pituitary-adrenal axis function. Journal of Biological Chemistry 282 27030-27036.
Wamil M, Andrew R, Chapman KE, Street J, Morton NM \& Seckl JR 2008 7-Oxysterols modulate glucocorticoid activity in adipocytes through competition for $11 \beta$-hydroxysteroid dehydrogenase type 1 . Endocrinology 149 5905-5918.

Wang H, Kouri G \& Wollheim CB 2005 ER stress and SREBP-1 activation are implicated in $\beta$-cell glucolipotoxicity. Journal of Cell Science 118 3905-3915.

Wei Y, Wang D, Topczewski F \& Pagliassotti MJ 2006 Saturated fatty acids induce endoplasmic reticulum stress and apoptosis independently of ceramide in liver cells. American Journal of Physiology 291 E275-E281.

White PC, Rogoff D, McMillan DR \& Lavery GG 2007 Hexose 6-phosphate dehydrogenase (H6PD) and corticosteroid metabolism. Molecular and Cellular Endocrinology 265-266 89-92.

White PC, Rogoff D \& McMillan DR 2008 Physiological roles of 11 $\beta$ hydroxysteroid dehydrogenase type 1 and hexose-6-phosphate dehydrogenase. Current Opinion in Pediatrics 20 453-457.

Yoshida H 2007 ER stress and diseases. FEBS Journal 274 630-658.

Zhang K \& Kaufman RJ 2008 From endoplasmic-reticulum stress to the inflammatory response. Nature 454 455-462.

Received in final form 24 November 2008

Accepted 5 December 2008

Made available online as an Accepted Preprint 5 December 2008 